practical ends. Thus among the members of the first Council are members of the Genetics Committee of the Medical Research Council and the Industrial Research Board, Prof. R. A. Fisher, director of the Galton Laboratory, Prof. Cyril Burt, representing psychology, and Prof. F. A. E. Crew, of Edinburgh. Prof. R. Ruggles Gates will act as chairman, Sir Laurence Halsey as honorary treasurer, and Mrs. C. B. S. Hodson as honorary secretary. To these are to be added representatives of the Royal Society of Medicine, the Statistical Society, the Medico-Psychological Association, the Eugenics Society, and the British Medical Association. In view of the consideration that the value of the Bureau as a place of reference for facts to medical men and other inquirers has been strongly stressed, it may be suggested that the representation of pure biology upon the Council stands in need of enlargement.

Lastly, on the important matter of finance. The Bureau at present depends entirely upon private subvention. It is estimated that now that some small sums have made it possible to set the Bureau at work, $\mathfrak{1 0 , 0 0 0}$ is required to keep it going for a period of five years, and an appeal for this amount has appeared in The Times of May 6 over the signatures of Prof. R. Ruggles Gates, Sir F. Gowland Hopkins, Lord Moynihan, Sir Arthur Keith, Sir Grafton Elliot-Smith and others. The purpose of the appeal is one which may heartily be commended to the generosity of all who are interested in scientific studies of man.

\title{
The Key Industries Act
}

$\mathrm{T}$ HE Key Industries Act may be termed appropriately the 'Fine Chemists' Charter' for, under its shelter, there has been built up in Great Britain a vigorous manufacturing industry giving employment to a number of chemists and chemical workers, which is to-day in a position to supply all the essential requirements in medicinals and fine chemicals needed by the British Empire, and is year by year adding products to its list.

It is a matter of history that the Act was first imposed as from October 1, 1921, with the object of protecting the manufacture in Great Britain of a number of substances and of scientific apparatus, which were essential for defence purposes, from unfair competition, particularly as many of the industries had arisen under war conditions and had been given no time to reorganise on a peace basis. The danger of the potential deficiencies in these industries was a serious one, and it was widely recognised that the words 'key industries' and 'safeguarding' had a very real significance.

The Key Industry Duties were extended and amended in 1926, and became due to expire in August 1936. They have now been extended in the Budget for a further period of ten years, following the report to this end of a committee set up by the Import Duties Advisory Board, which has made a searching study of the question. A useful survey of the working of the Act appears in the April issue of the Industrial Chemist.

There has been some suggestion that the Act should be allowed to lapse and the products transferred to the Import Duties Act, but cogent arguments were produced against the change, particularly because it involved a change in the administrative machinery which has been worked so efficiently by the Board of Trade during the fifteen years of 'safeguarding'. It will be possible in the future, however, to impose extra duties beyond the $33 \frac{1}{3}$ per cent ad valorem on individual substances coming under 'safeguarding' if the Import Duties Advisory Committee so determines.

It is, of course, known that the Act covers optical and scientific glass, porcelain and scientific instruments, gauges and certain other materials besides chemicals. These latter are defined as "all synthetic fine chemicals", "analytical reagents, all other fine chemicals", and from time to time inquiries before a tribunal have been held to decide whether certain substances came within this definition. In December 1933 a "preparation", as distinct from a chemically identifiable compound, was added to the list against the opposition of the Board of Trade, a decision which did not find favour in medical circles.

It is unquestionable that the fine chemical industry of Great Britain, and indeed the chemical industry as a whole, has benefited greatly from the imposition of the duties. Its continuance will give a reasonable period of security in which long-term plans can be undertaken, and research and the training of the necessary staff encouraged. 